\title{
Tissue distribution and excretion kinetics of orally administered silica nanoparticles in rats
}

\author{
This article was published in the following Dove Press journal: \\ International Journal of Nanomedicine \\ 15 December 2014 \\ Number of times this article has been viewed
}

\author{
Jeong-A Lee' \\ Mi-Kyung Kim' \\ Hee-Jeong Paek' \\ Yu-Ri Kim ${ }^{2}$ \\ Meyoung-Kon Kim² \\ Jong-Kwon $\mathrm{Lee}^{3}$ \\ Jayoung Jeong ${ }^{3}$ \\ Soo-Jin Choi'
}

'Department of Food Science and Technology, Seoul Women's

University, Seoul, Republic of Korea;

${ }^{2}$ Department of Biochemistry and

Molecular Biology, Korea University

Medical School and College, Seoul,

Republic of Korea; ${ }^{3}$ Toxicological

Research Division, National Institute

of Food and Drug Safety Evaluation,

Chungchungbuk-do, Republic of

Korea
Correspondence: Soo-Jin Choi

Department of Food Science and

Technology, Seoul Women's University,

62I Hwarang-ro, Nowon-gu,

Seoul 139-774, Republic of Korea

Tel +82 29705634

Fax +82 29705977

Email sjchoi@swu.ac.kr
Purpose: The effects of particle size on the tissue distribution and excretion kinetics of silica nanoparticles and their biological fates were investigated following a single oral administration to male and female rats.

Methods: Silica nanoparticles of two different sizes (20 nm and $100 \mathrm{~nm}$ ) were orally administered to male and female rats, respectively. Tissue distribution kinetics, excretion profiles, and fates in tissues were analyzed using elemental analysis and transmission electron microscopy

Results: The differently sized silica nanoparticles mainly distributed to kidneys and liver for 3 days post-administration and, to some extent, to lungs and spleen for 2 days post-administration, regardless of particle size or sex. Transmission electron microscopy and energy dispersive spectroscopy studies in tissues demonstrated almost intact particles in liver, but partially decomposed particles with an irregular morphology were found in kidneys, especially in rats that had been administered $20 \mathrm{~nm}$ nanoparticles. Size-dependent excretion kinetics were apparent and the smaller $20 \mathrm{~nm}$ particles were found to be more rapidly eliminated than the larger $100 \mathrm{~nm}$ particles. Elimination profiles showed $7 \%-8 \%$ of silica nanoparticles were excreted via urine, but most nanoparticles were excreted via feces, regardless of particle size or sex.

Conclusion: The kidneys, liver, lungs, and spleen were found to be the target organs of orally-administered silica nanoparticles in rats, and this organ distribution was not affected by particle size or animal sex. In vivo, silica nanoparticles were found to retain their particulate form, although more decomposition was observed in kidneys, especially for $20 \mathrm{~nm}$ particles. Urinary and fecal excretion pathways were determined to play roles in the elimination of silica nanoparticles, but $20 \mathrm{~nm}$ particles were secreted more rapidly, presumably because they are more easily decomposed. These findings will be of interest to those seeking to predict potential toxicological effects of silica nanoparticles on target organs.

Keywords: biological fate, size effect, target organ

\section{Introduction}

Silica nanoparticles have attracted much attention for industrial and biomedical applications, such as for use as additives and in printer toners, varnishes, pharmaceutics, cosmetics, and coating materials. ${ }^{1,2}$ These wide-ranging applications stem from the properties of silica nanoparticles, which include easy synthesis, low toxicity, hydrophilicity, and the ease with which their surfaces can be modified or functionalized. ${ }^{3-5}$ Hence, silica nanoparticles have been extensively developed for biological purposes for use as biomarkers, biosensors, DNA or drug delivery, and cancer therapy. ${ }^{6-10}$

In this context, many studies have recently focused on biological effects of silica nanoparticles at different levels, such as on their cytotoxicities, blood compatibilities, 
acute and repeat dose toxicities, and biokinetics, ${ }^{11-19}$ which are currently hot issues in the nanotoxicology field. However, the kinetic behaviors of silica nanoparticles at the systemic level, including their pharmacokinetics, tissue distributions, and clearances, remain unclear. In vivo biokinetic studies can be conducted by systematic and quantitative analyses of plasma, tissues, urine or feces, and other biological samples in whole animals after exposure to assess absorption, distribution, metabolism, and excretion. An understanding of the kinetic behaviors of silica nanoparticles is of importance in the context of determining absorption amounts, target organs, and residence times, which are essential for the prediction of potential adverse effects in the short- and long-term. Some researchers have recently described the biodistribution and excretion kinetics of silica nanoparticles. ${ }^{20-25}$ However, most of this information was obtained after intravenous injection, which introduces nanoparticles directly into the circulatory system. In practice, oral administration is important, for example, in food or water, and results in kinetic behaviors unlike those associated after intravenous injection because nanoparticles must encounter stomach acid and cross the epithelium of the gastrointestinal (GI) tract in order to reach the blood circulation. In addition, even after GI transit, nanoparticles are carried to the liver via the portal vein before entering the systemic circulation and, thus, are subject to metabolic processes that evidently reduce bioavailability.

The biokinetics of silica nanoparticles at the systemic level has been less extensively explored than other inorganic nanoparticles, which appears to be due to the difficulty of detecting silica nanoparticles in biological matrices. ${ }^{20}$ The major approaches used to trace and determine their kinetics in vivo are based on the use of dye-conjugated or dyeembedded particles and subsequent fluorescence detection by microscopy or some other imaging modality. ${ }^{20,23,24}$ However, this strategy is limited with respect to the interpretation of results as dye-conjugated particles are structurally modified and, thus, molecular weights and surface charges are changed. These changes could affect biological interactions at the systemic level and could eventually modify kinetic behaviors. Furthermore, the stabilities of dye-conjugated or dye-embedded particles in whole animals are also necessary considerations that complicate the interpretations of quantitative analyses. In our previous study, we devised a quantitative analytical method for measuring the amounts of silica nanoparticles in biological matrices based on a lithium borate fusion technique with a molybdenum blue spectrophotometric method. ${ }^{26}$ In the present study, we evaluated the tissue distributions and elimination kinetics of $20 \mathrm{~nm}$ and
$100 \mathrm{~nm}$ silica nanoparticles after administering a single oral dose to male and female rats. In addition, the biological fates of the silica nanoparticles in target organs were determined by transmission electron microscopy (TEM).

\section{Materials and methods Preparation and characterization of nanoparticles}

Colloidal silica nanoparticles $(20 \mathrm{~nm}$ and $100 \mathrm{~nm}$, dispersed in distilled water [DW]) were purchased from $\mathrm{E}$ and B Nanotech Co, Ltd. (Gyeonggi-do, Republic of Korea) and analyzed by TEM (JEM-1010; JEOL, Tokyo, Japan). The surface charges (zeta potentials) of nanoparticles were determined using a zeta potentiometer (Zetasizer Nano ZS system; Malvern Instruments, Malvern, UK).

\section{Animals}

Five-week-old male and female Sprague Dawley rats weighing 120-140 g were purchased from G-Bio (Seoul, Republic of Korea). The animals were housed in plastic lab animal cages in a ventilated room, which was maintained at $20^{\circ} \mathrm{C} \pm 2^{\circ} \mathrm{C}$ and $60 \% \pm 10 \%$ relative humidity under a 12 -hour light/dark cycle. Water and commercial laboratory complete food were provided ad libitum. Animals were acclimated to this environment for 7 days before treatment. All animal experiments were performed in compliance with the guidelines issued by the Animal and Ethics Review Committee of Seoul Women's University.

\section{Dosing and sample collection}

Four groups of male and of female rats ( $n=6$ per group) were administered a single dose of 500 or $1,000 \mathrm{mg} / \mathrm{kg}$ of nanoparticles ( $20 \mathrm{~nm}$ and $100 \mathrm{~nm}$ ) by oral gavage. In addition, six rats were administered an equivalent volume of DW as controls. Body weights, behavioral changes, and other symptoms were carefully recorded daily after treatment.

For the tissue distribution study, samples of brain, heart, kidneys, liver, lungs, spleen, and testes or ovaries were collected at 1 and 6 hours, and 1, 2, 3, and 7 days postadministration after $\mathrm{CO}_{2}$-induced euthanasia.

To evaluate excretion profiles, urine and feces were collected at 10 hours, and 1, 2, 3, 4, 5, 6, 7, 8, 9, and 10 days post-administration.

\section{Quantitative analysis of silicon}

Silicon ( $\mathrm{Si}$ ) analysis in biological samples was performed as previously described. ${ }^{26}$ Briefly, a $100 \mathrm{mg}$ sample was placed in a graphite crucible and $200 \mathrm{mg}$ of lithium metaborate 
( $\mathrm{LiBO}_{2}$; Sigma-Aldrich, St Louis, MO, USA) was added. After mixing, the crucible was heated in a furnace for 25 minutes at $1,025^{\circ} \mathrm{C}$, and then $2 \mathrm{~mL}$ of distilled deionized water (DDW), $2 \mathrm{~mL}$ of nitric acid $\left(\mathrm{HNO}_{3} ; 70 \%\right), 2 \mathrm{~mL}$ scandium oxide solution $(250 \mu \mathrm{g} / \mathrm{mL})$, and one drop of hydrogen peroxide $\left(\mathrm{H}_{2} \mathrm{O}_{2}\right)$ were added. This mixture was then heated on a hot plate until the ash had been completely dissolved. The remaining solution was then removed by heating, and $5 \mathrm{~mL}$ of DDW was added. For Si quantification by the molybdenum blue method, 2 to 3 drops of hydrofluoric acid (48\%) were added to $1 \mathrm{~mL}$ of this solution, and $5 \mathrm{~mL}$ of ammonium molybdate solution $(65 \mathrm{~g} / \mathrm{L})$ and $4 \mathrm{~mL}$ of hydrogen chloride ( $\mathrm{HCl} ; 3.7 \%$ ) were added. After adding $20 \mathrm{~mL}$ of DDW, the mixture was left to stand for 30 minutes, and $2 \mathrm{~mL}$ of oxalic acid, $2 \mathrm{~mL}$ of sodium sulfite solution $(150 \mathrm{~g} / \mathrm{L})$, and $5 \mathrm{~mL}$ of sulfuric acid were added. The mixture was then left to stand for 3 minutes. Finally, $1 \mathrm{~mL}$ of stannous chloride solution ( $\mathrm{SnCl}_{2} 50 \mathrm{~g}$ in $100 \mathrm{~mL}$ of $\mathrm{HCl}$ and $50 \mathrm{~mL}$ of DDW) was added and absorbance was measured at $820 \mathrm{~nm}$ (SMP500-16509SICX; Molecular Devices LLC, Sunnyvale, CA, USA).

Quantitative analysis was carried out by external fourpoint-calibration with internal standard correction using spiking experiments.

\section{TEM study}

Representative organs, such as livers and kidneys, were collected from three silica nanoparticle $(1,000 \mathrm{mg} / \mathrm{kg})$-administered male rats 48 hours post-administration. One group of three rats was administered DW as a control. Samples were fixed using modified Karnovsky's fixative (2\% paraformaldehyde and $2 \%$ glutaraldehyde in $0.05 \mathrm{M}$ sodium cacodylate buffer [pH 7.2]), postfixed with $1: 1$ solution of $2 \%$ osmium tetroxide and $0.1 \mathrm{M}$ sodium cacodylate for 2 hours at $4{ }^{\circ} \mathrm{C}$, and then stained with uranyl acetate. Samples were then dehydrated with ethanol and blocks were prepared using Spurr's resin. Blocks were sectioned using an ultramicrotome (MT-X; Boeckeler Instruments, Inc., Tucson, AZ, USA) and, after coating with high purity carbon rod (Ted Pella, Inc., Redding, CA, USA), TEM images were obtained using a Tecnai G2 unit, equipped with an energy dispersive spectroscopy (EDS) facility, at the Korea Basic Science Institute (KBSI; Gwangju Branch, Republic of Korea).

\section{Statistical analysis}

The data are presented as means \pm standard deviations. For statistical analysis, experimental values were compared with corresponding control values. One-way analysis of variance in SAS software (Tukey's Test, Version 11.0; SAS Institute Inc., Cary, NC, USA) was used to determine the significances of differences between experimental groups and controls. Statistical significance was accepted for $P$-values of $<0.05$.

\section{Results \\ Characterization of silica nanoparticles}

Colloidal silica nanoparticles of $20 \mathrm{~nm}$ and $100 \mathrm{~nm}$ were characterized by TEM and by measuring zeta potentials (Table 1). As previously reported, ${ }^{26}$ the average particle sizes of these silica nanoparticles were $15 \pm 3 \mathrm{~nm}$ and $89 \pm 14 \mathrm{~nm}$, respectively, and both had a spherical morphology and were negatively charged in DW at $\mathrm{pH}$ 7.0.

\section{Effects of silica nanoparticles on body weights and symptoms}

Survival rates, body weights, behaviors, and symptoms were carefully observed for 14 days post-administration. Male and female rats that were administered the two differently sized silica nanoparticles up to $1,000 \mathrm{mg} / \mathrm{kg}$ showed no body weight loss, abnormal behaviors, or symptoms as compared with untreated controls (Figure 1). No significant difference in body weights was found between treated and control animals.

\section{Tissue distribution}

The biodistribution of silica nanoparticles was examined in brain, kidneys, liver, lungs, spleen, and ovaries/testes. Total Si concentrations in tissues were analyzed, as described above, by determining increases in total Si levels in silicaadministered rats versus untreated controls. Si levels were found to be significantly higher in kidneys, liver, lungs, and spleen of treated rats regardless of dose, particle size, or sex (Figure 2). Notably, high Si concentrations were found in kidneys and livers at 6 hours to 3 days post-administration, whereas elevated Si levels were detected at 6 hours to 2 days in lungs and spleens. Silica nanoparticles did not accumulate significantly in brains, ovaries, or testes. Furthermore, tissue distributions were similar regardless of particle size or sex. The increases in Si concentrations that were found are summarized in Table 2. Increases in Si concentrations in the GI tract (esophagus, stomach, and intestine) were not detected at 7 days post-administration.

Table I Particle sizes and zeta potentials of silica nanoparticles

\begin{tabular}{lll}
\hline & Measured particle size $(\mathbf{n m})^{\mathbf{a}}$ & ${\text { Zeta potential }(\mathbf{m V})^{\mathbf{b}}}$ \\
\hline $20 \mathrm{~nm}$ & $15 \pm 3$ & $-60 \pm 7$ \\
$100 \mathrm{~nm}$ & $89 \pm 14$ & $-76 \pm 3$ \\
\hline
\end{tabular}

Notes: average particle size was measured by randomly selecting 200 particles in TEM images; 'beta potentials were measured in distilled water $(\mathrm{pH} 7.0)$. 
A

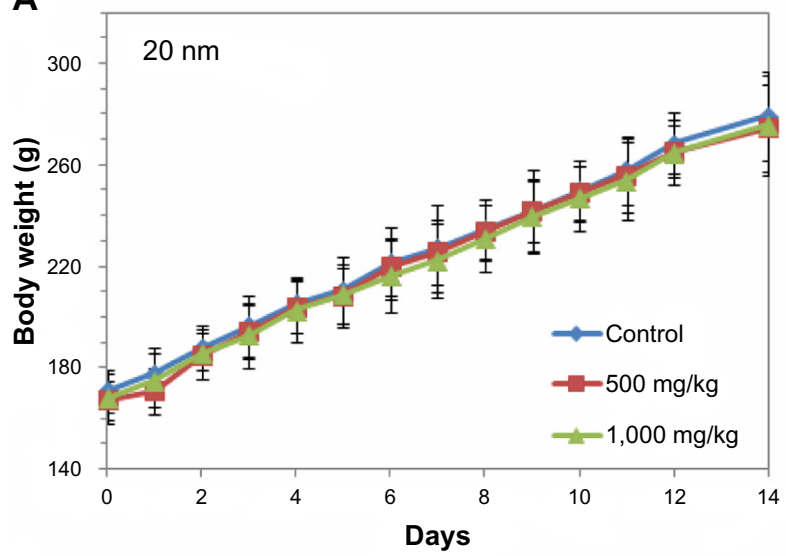

C

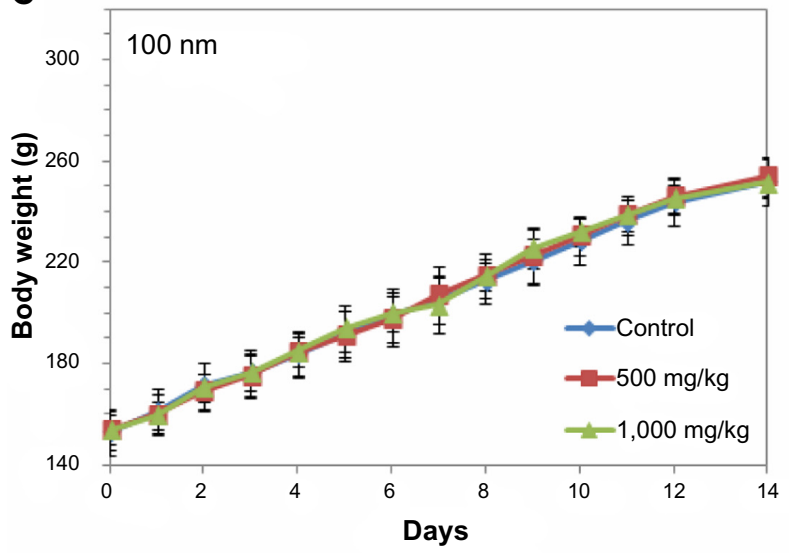

B

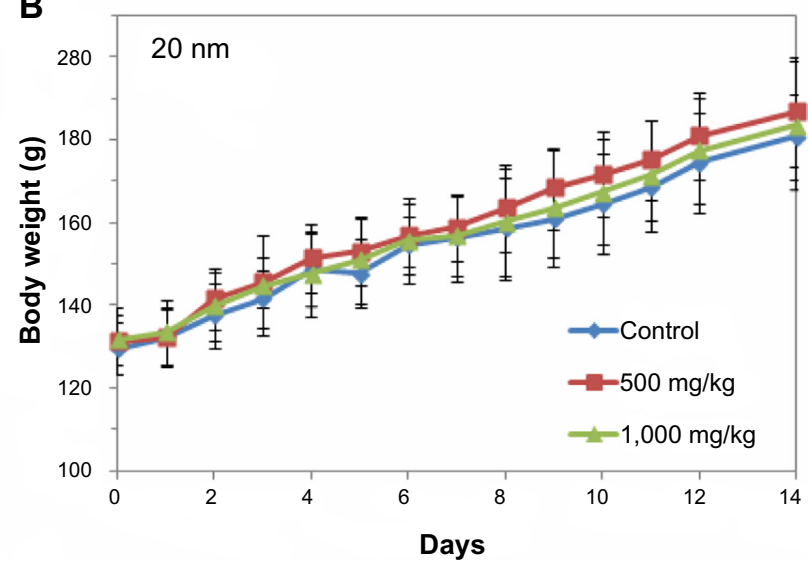

D

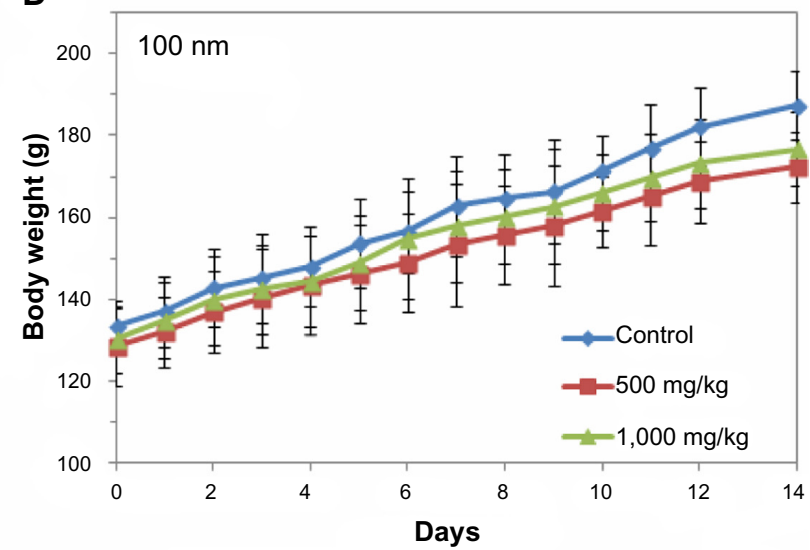

Figure I Body weight gains of male and female rats administered $20 \mathrm{~nm}$ or $100 \mathrm{~nm}$ silica nanoparticles.

Notes: (A) Male rats administered $20 \mathrm{~nm}$ silica nanoparticles. (B) Female rats administered $20 \mathrm{~nm}$ silica nanoparticles. (C) Male rats administered I00 nm silica nanoparticles. (D) Female rats administered $100 \mathrm{~nm}$ silica nanoparticles. No significant difference was observed versus untreated controls.

\section{In vivo fate of silica nanoparticles in tissues}

TEM analysis of organs from silica-administered rats was carried out to confirm tissue distributions and to determine the biological fates of nanoparticles in target tissues. As shown in Figure 3, silica nanoparticles of both $20 \mathrm{~nm}$ and $100 \mathrm{~nm}$ were observed in liver, and these had the same spherical morphology and particle sizes observed prior to administration (Table 1). In particular, differently sized silica nanoparticles were localized in hepatocytes as well as in nuclei. On the other hand, irregular particle shapes were observed in kidneys, and more so in rats treated with $20 \mathrm{~nm}$ silica nanoparticles. TEM-EDS confirmed the presence of $\mathrm{Si}$ in the particulate forms in livers and kidneys.

\section{Excretion}

The excretion kinetics of silica nanoparticles was evaluated by measuring increases in Si levels in urine and feces. Significantly, higher Si concentrations in urine were detected, regardless of sex, at 1-2 days and 1-5 days after administering
$20 \mathrm{~nm}$ silica nanoparticles at 500 or $1,000 \mathrm{mg} / \mathrm{kg}$, respectively (Figure 4). However, elimination in urine was slower after the administration of $100 \mathrm{~nm}$ particles, which produced elevated Si levels at 1-3 days and 1-6 days at doses of 500 and $1,000 \mathrm{mg} / \mathrm{kg}$, respectively. A similar tendency was found for fecal excretion profiles; Si concentrations were elevated at 1-3 days and at 1-4 days after the administration of $20 \mathrm{~nm}$ and $100 \mathrm{~nm}$ nanoparticles, respectively, at doses of 500 and $1,000 \mathrm{mg} / \mathrm{kg}$, showing size-dependent elimination kinetics. It is worth noting that much higher Si levels were detected in feces than in urine. Table 3 summarizes the total excretion values of differently sized silica nanoparticles. We estimate that $7 \%-8 \%$ of nanoparticles were excreted in urine and $75 \%-80 \%$ via feces. Particle size and sex were not found to influence excretion values.

\section{Discussion}

The tissue distribution, excretion, and in vivo fates of colloidal silica nanoparticles $(20 \mathrm{~nm}$ and $100 \mathrm{~nm})$ were investigated after a single oral administration in male 
A
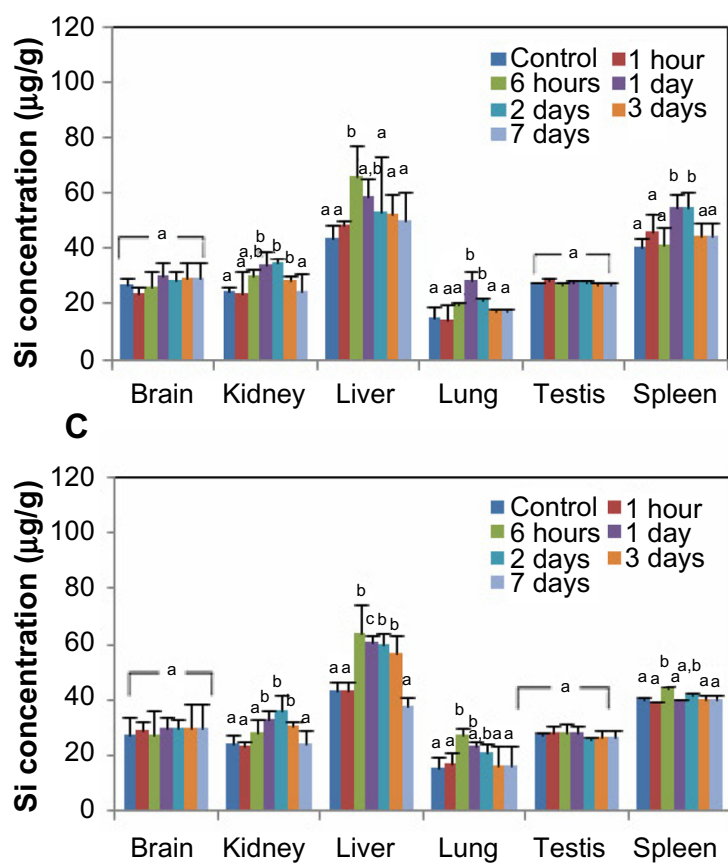

E

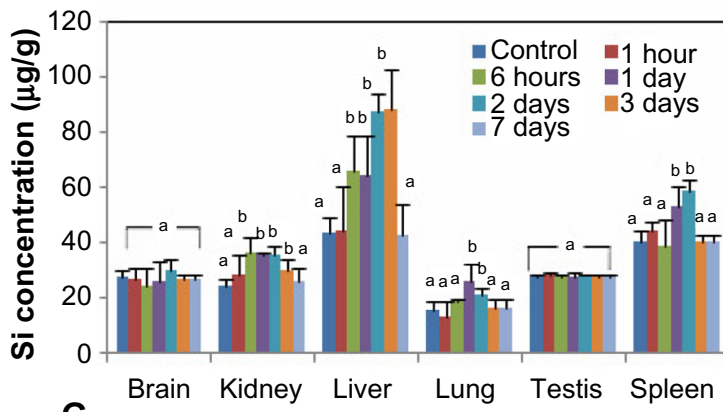

G

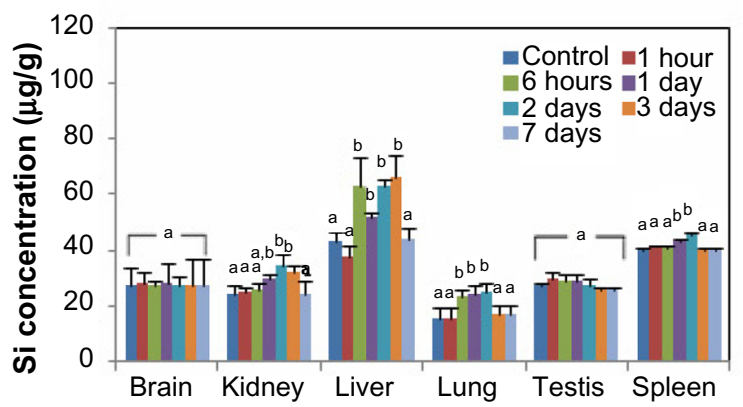

\section{B}
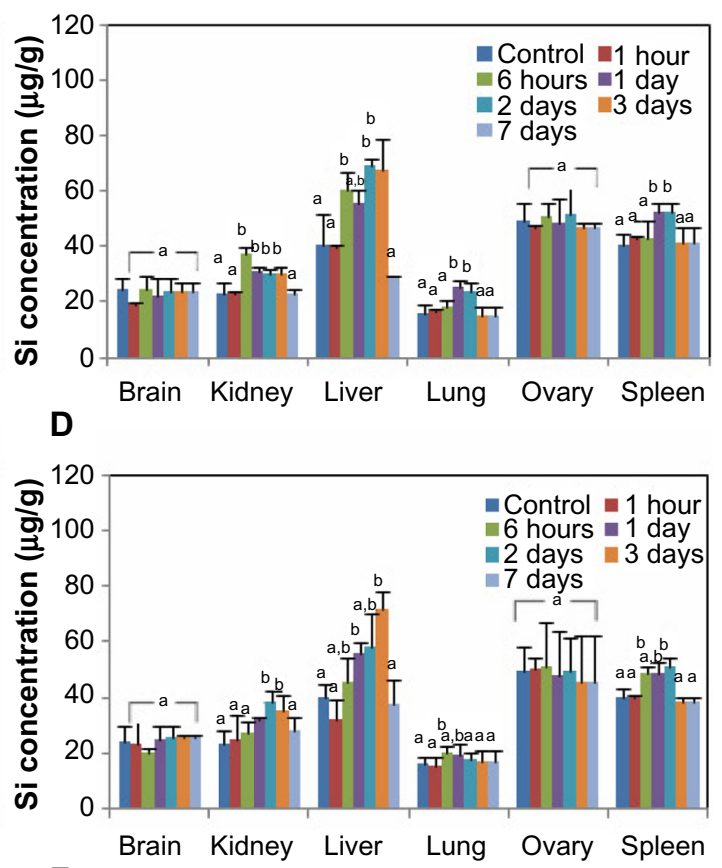

$\mathbf{F}$
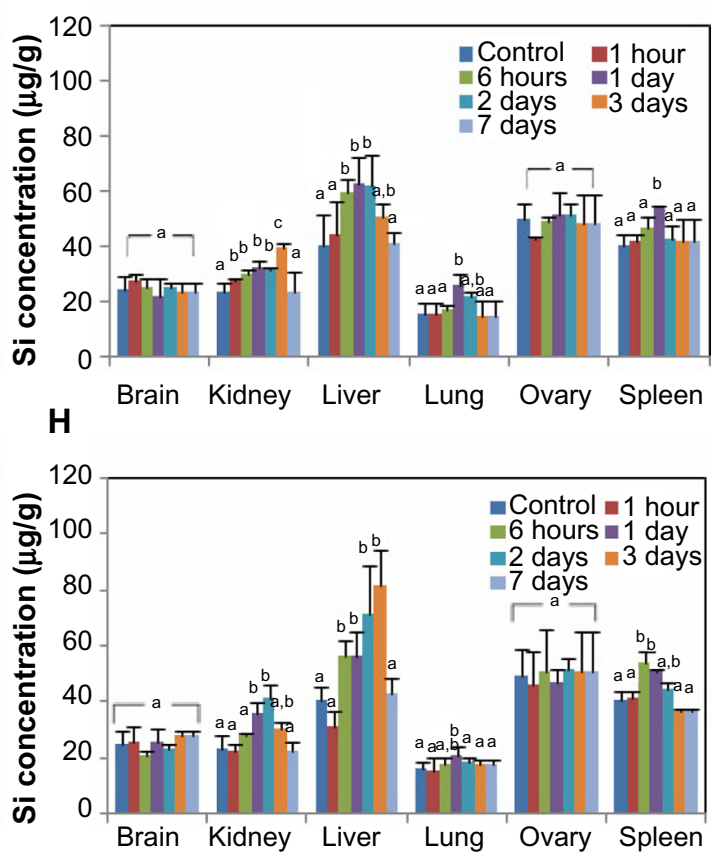

Figure 2 Tissue distributions of silica nanoparticles in rats after a single oral administration.

Notes: (A) Oral administration of $500 \mathrm{mg} / \mathrm{kg}$ of $20 \mathrm{~nm}$ nanoparticles in males. (B) Oral administration of $500 \mathrm{mg} / \mathrm{kg}$ of $20 \mathrm{~nm}$ nanoparticles in females. (C) Oral administration of $500 \mathrm{mg} / \mathrm{kg}$ of $100 \mathrm{~nm}$ in males. (D) Oral administration of $500 \mathrm{mg} / \mathrm{kg}$ of $100 \mathrm{~nm}$ in females. (E) Oral administration of I,000 mg/kg of $20 \mathrm{~nm}$ nanoparticles in males. (F) Oral administration of $1,000 \mathrm{mg} / \mathrm{kg}$ of $20 \mathrm{~nm}$ nanoparticles in females. (G) Oral administration of I,000 mg/kg of $100 \mathrm{~nm}$ in males. (H) Oral administration of I,000 mg/kg of $100 \mathrm{~nm}$ in females. There are statistically significant differences between columns labeled (a) and columns labeled (b) $(P<0.05)$.

Abbreviation: Si, silicon.

and female rats. Particle sizes of $20 \mathrm{~nm}$ and $100 \mathrm{~nm}$ were examined, because the sizes of most of the nanoparticles developed fall in the range $1-100 \mathrm{~nm}$, and because these sizes varied enough to evaluate the effect of particle size on biokinetics.
After a single-dose administration of silica nanoparticles, survival rates and body weight gains were unaffected at dosages of up to $1,000 \mathrm{mg} / \mathrm{kg}$. Furthermore, no abnormal behaviors or symptoms, such as a decrease in food or water intake, diarrhea, loss of movement, or changes in pupil size or eye 
Table 2 Tissue distributions of differently sized silica nanoparticles in rats after a single oral administration

\begin{tabular}{|c|c|c|c|c|c|c|c|c|c|c|}
\hline & \multicolumn{2}{|l|}{ Control } & \multicolumn{4}{|c|}{$500 \mathrm{mg} / \mathrm{kg}$} & \multicolumn{4}{|c|}{$1,000 \mathrm{mg} / \mathrm{kg}$} \\
\hline & \multirow[t]{2}{*}{ Male } & \multirow[t]{2}{*}{ Female } & \multicolumn{2}{|l|}{$20 \mathrm{~nm}$} & \multicolumn{2}{|l|}{$100 \mathrm{~nm}$} & \multicolumn{2}{|l|}{$20 \mathrm{~nm}$} & \multicolumn{2}{|l|}{$100 \mathrm{~nm}$} \\
\hline & & & Male & Female & Male & Female & Male & Female & Male & Female \\
\hline Brain $(\mu g / g)$ & $104 \pm 7$ & $103 \pm 8$ & $109 \pm 3$ & $105 \pm 16$ & $104 \pm 10$ & $97 \pm 3$ & $107 \pm 10$ & $93 \pm 14$ & $107 \pm 8$ & $100 \pm 9$ \\
\hline Kidneys $(\mu g / g)$ & $90 \pm 7$ & $80 \pm 11$ & $144 \pm 6 *$ & $|3| \pm 9 *$ & $132 \pm 18 *$ & $|32 \pm 2| *$ & $160 \pm 23 *$ & $140 \pm 15^{*}$ & $139 \pm 7^{*}$ & $135 \pm 18^{*}$ \\
\hline Liver $(\mu g / g)$ & $175 \pm 14$ & $173 \pm 15$ & $261 \pm 13^{*}$ & $231 \pm 14 *$ & $25 I \pm 3 I *$ & $235 \pm 13^{*}$ & $273 \pm 43 *$ & $249 \pm 18^{*}$ & $255 \pm 38 *$ & $256 \pm 10 *$ \\
\hline Lungs ( $\mu g / g)$ & $59 \pm 6$ & $59 \pm 5$ & $72 \pm 5^{*}$ & $69 \pm 8 *$ & $82 \pm 6 *$ & $76 \pm 6 *$ & $78 \pm 10^{*}$ & $76 \pm 3 *$ & $84 \pm 7 *$ & $77 \pm 8 *$ \\
\hline Spleen $(\mu g / g)$ & $144 \pm 17$ & $144 \pm 17$ & $198 \pm 13^{*}$ & $|89 \pm 1|^{*}$ & $193 \pm 20 *$ & $192 \pm 22 *$ & $218 \pm 17^{*}$ & $202 \pm 25^{*}$ & $200 \pm 22 *$ & $197 \pm 26 *$ \\
\hline Ovary/testis $(\mu g / g)$ & $115 \pm 14$ & $160 \pm 16$ & $104 \pm 14$ & $162 \pm 22$ & $112 \pm 6$ & $|60 \pm| \mid$ & $103 \pm 17$ & $158 \pm 23$ & $120 \pm 10$ & $169 \pm 19$ \\
\hline Total $(\mu g / g)$ & $688 \pm 65$ & $720 \pm 72$ & $885 \pm 51 *$ & $890 \pm 77^{*}$ & $873 \pm 99 *$ & $892 \pm 78^{*}$ & $939 \pm 19 *$ & $919 \pm 98 *$ & $904 \pm 92 *$ & $933 \pm 90 *$ \\
\hline
\end{tabular}

Note: *Significantly different from the control group $(P<0.05)$.

pigmentation, were observed during the 14 days post-administration. These results suggest that orally administered silica nanoparticles do not exhibit acute toxicity. Furthermore, the same results were obtained for different particle sizes in male and female rats. Low toxicity of silica nanoparticles following oral administration was also recently reported by $\mathrm{Fu}$ et al; ${ }^{27}$ $110 \mathrm{~nm}$ mesoporous silica nanoparticles caused no immediate toxicity, such as loss of appetite, loss of weight, death, or passive behaviors, in mice after oral administration of 5,000 $\mathrm{mg} / \mathrm{kg}$. Ivanov et al demonstrated that intravenously injected silica nanoparticles $(13 \mathrm{~nm}, 7 \mathrm{mg} / \mathrm{kg})$ are relatively biocompatible nanomaterials when considering acute toxicity. ${ }^{28}$ It seems that silica nanoparticles do not exhibit acute toxicity at the dosages used in this study, although more extended study is needed to confirm their toxicity, for example, by biochemical analysis and histopathological examination.

Our previous study showed that plasma concentrationtime curves for single oral doses of silica nanoparticles (20 $\mathrm{nm}$ and $100 \mathrm{~nm}$ ) at 500 and $1,000 \mathrm{mg} / \mathrm{kg}$ rapidly decreased within 4 hours and 10 hours, respectively, in a dose-dependent manner, after oral administration to rats, regardless of particle size or sex. ${ }^{26}$ Absorption amount was determined to be low, ranging from $6.6 \%-9.7 \%$, without being affected by particle size or sex. ${ }^{26}$ In our biodistribution study, significantly elevated Si concentrations were detected in kidneys, liver, lungs, and spleens within 3 days, but returned to normal level after 7 days. When tissue distribution kinetics was compared, nanoparticles were found to persist longer in kidneys and liver than in lungs and spleen (3 days versus 1-2 days), and tissue distribution patterns were not dependent on particle size or sex. Furthermore, the fact that silica nanoparticles were found in liver, lungs, and spleen also indicates that the nanoparticles were sequestered into organs by the mononuclear phagocytic system, also known as the reticuloendothelial system (RES), which implies phagocytosis is involved in their uptake. Increased Si levels in kidneys can be closely related to the excretion pathway of the silica nanoparticles in urine. Most biodistribution studies on silica nanoparticles have been conducted by administering a single intravenous injection. He et $\mathrm{al}^{23}$ reported the accumulation of spherical mesoporous silica nanoparticles $(80-360 \mathrm{~nm})$ labeled with fluorescein isothiocyanate in liver and spleen
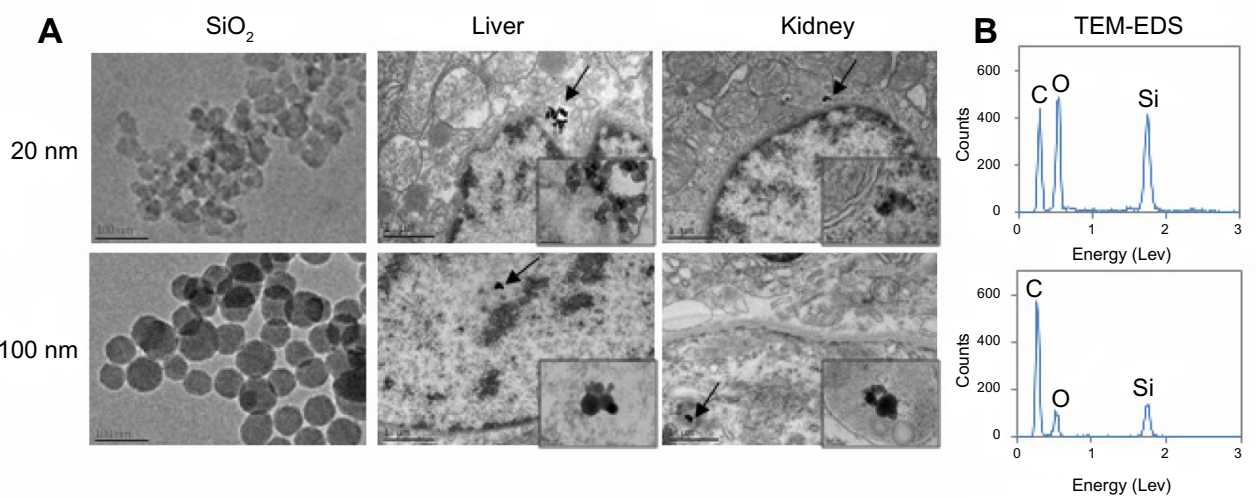

Figure 3 TEM images of silica nanoparticles before administration and liver and kidney tissues collected at 48 hours after the oral administration of $20 \mathrm{~nm}$ or $100 \mathrm{~nm}$ sized nanoparticles.

Notes: (A) Higher magnification of the tissues where nanoparticles are present, indicated by arrow. (B) TEM-EDS images show the presence of Si in the particulate forms in the tissues.

Abbreviations: EDS, energy dispersive spectroscopy; $\mathrm{Si}$, silicon; $\mathrm{SiO}_{2}$, silica; TEM, transmission electron microscopy. 
A
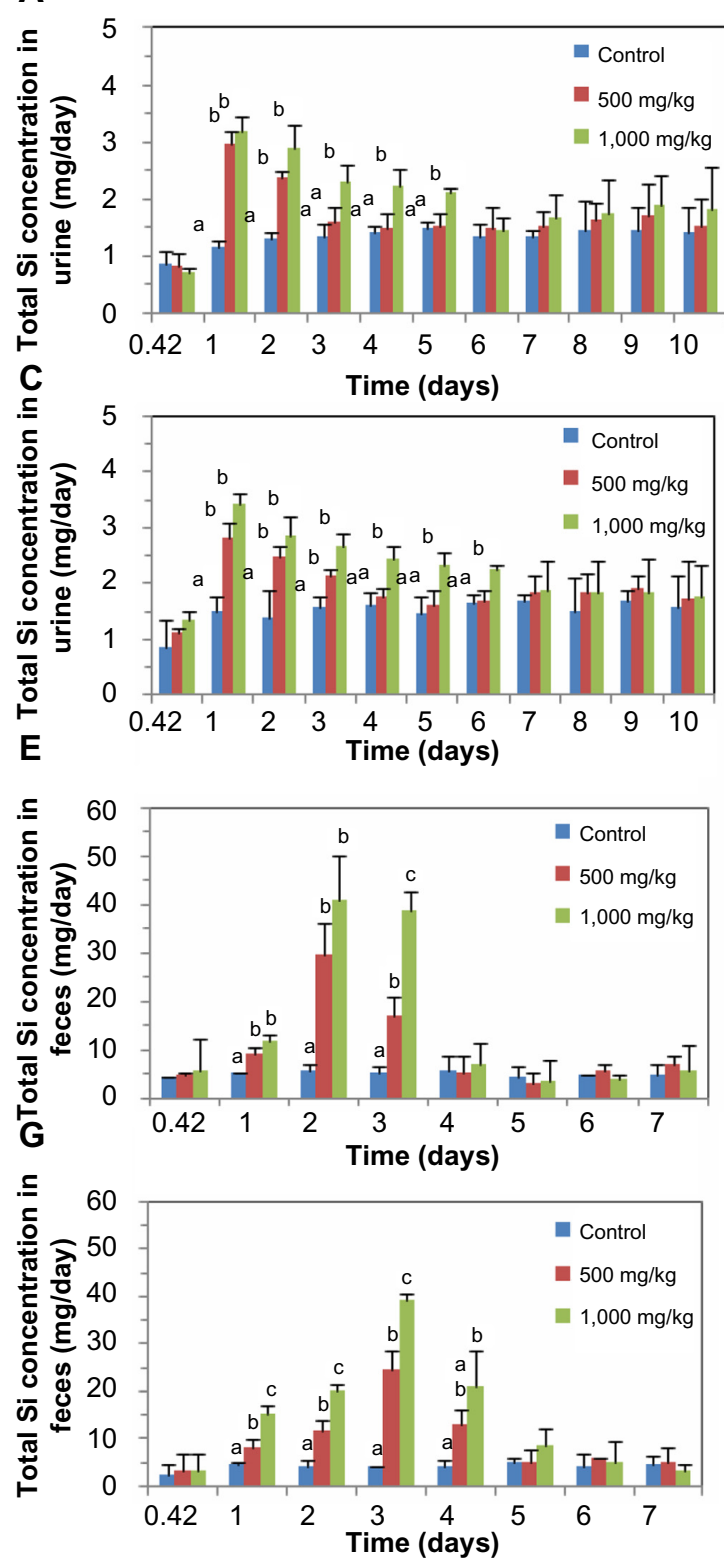

B
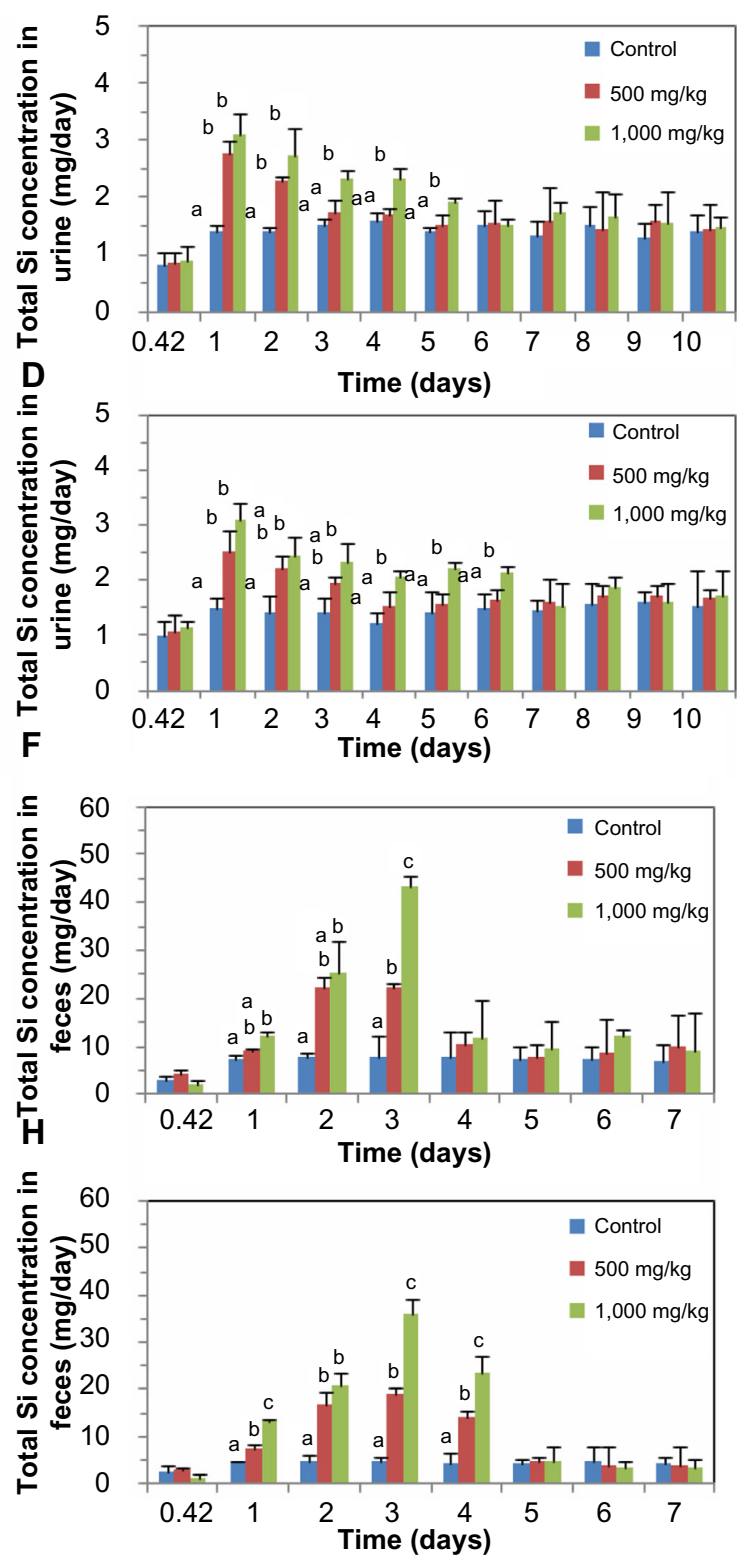

Figure 4 Excretion kinetics of silica nanoparticles.

Notes: (A) Excretion of $20 \mathrm{~nm}$ silica nanoparticles via urine in males. (B) Excretion of $20 \mathrm{~nm}$ silica nanoparticles via urine in females. (C) Excretion of I00 nm silica nanoparticles via urine in males. (D) Excretion of $100 \mathrm{~nm}$ silica nanoparticles via urine in females. (E) Excretion of $20 \mathrm{~nm}$ silica nanoparticles via feces in males. (F) Excretion of $20 \mathrm{~nm}$ silica nanoparticles via feces in females. (G) Excretion of $100 \mathrm{~nm}$ silica nanoparticles via feces in males. (H) Excretion of $100 \mathrm{~nm}$ silica nanoparticles via feces in females. There are statistically significant differences between columns labeled (a), columns labeled (b), and columns labeled (c) $(P<0.05)$.

Abbreviation: Si, silicon.

Table 3 Urine and fecal excretion values of differently sized silica nanoparticles in rats after a single oral administration

\begin{tabular}{|c|c|c|c|c|c|c|c|c|}
\hline & \multicolumn{4}{|l|}{$500 \mathrm{mg} / \mathrm{kg}$} & \multicolumn{4}{|c|}{$1,000 \mathrm{mg} / \mathrm{kg}$} \\
\hline & \multicolumn{2}{|l|}{$20 \mathrm{~nm}$} & \multicolumn{2}{|l|}{$100 \mathrm{~nm}$} & \multicolumn{2}{|l|}{$20 \mathrm{~nm}$} & \multicolumn{2}{|l|}{$100 \mathrm{~nm}$} \\
\hline & Male & Female & Male & Female & Male & Female & Male & Female \\
\hline Excretion via urine (\%) & $7.65 \pm 0.88$ & $7.43 \pm 0.53$ & $7.62 \pm 0.84$ & $7.56 \pm 0.35$ & $6.73 \pm 0.55$ & $7.09 \pm 0.50$ & $7.11 \pm 0.69$ & $7.16 \pm 0.59$ \\
\hline $\begin{array}{l}\text { Excretion amount } \\
\text { via urine }(\mathrm{mg})\end{array}$ & $4.19 \pm 0.48$ & $3.53 \pm 0.25$ & $4.17 \pm 0.46$ & $3.59 \pm 0.17$ & $7.39 \pm 0.60$ & $6.73 \pm 0.47$ & $7.79 \pm 0.76$ & $6.79 \pm 0.56$ \\
\hline Excretion via feces (\%) & $77.25 \pm 6.50$ & $79.09 \pm 6.16$ & $78.52 \pm 5.34$ & $79.52 \pm 5.99$ & $74.60 \pm 7.38$ & $75.74 \pm 10.27$ & $75.08 \pm 5.18$ & $76.54 \pm 8.99$ \\
\hline $\begin{array}{l}\text { Excretion amount } \\
\text { via feces }(\mathrm{mg})\end{array}$ & $42.29 \pm 3.56$ & $37.53 \pm 2.92$ & $42.99 \pm 2.92$ & $37.73 \pm 2.84$ & $81.68 \pm 8.08$ & $71.88 \pm 9.75$ & $82.21 \pm 5.67$ & $71.62 \pm 8.98$ \\
\hline
\end{tabular}

Note: No significant differences were observed between animals administered the same doses. 
and to a lesser extent in lungs, kidneys, and heart in rats for 5 days post-injection. He et $\mathrm{al}^{20}$ demonstrated a similar distribution pattern for $45 \mathrm{~nm}$ silica nanoparticles using an in vivo fluorescence imaging system. Borak et al reported that $150 \mathrm{~nm}$ silica nanoparticles accumulated primarily in the lungs and kidneys, and less so in hearts and liver at 4 days post-injection. ${ }^{29}$ Huang et al reported that mesoporous silica nanoparticles with different aspect ratios mainly accumulated in the RES of liver, spleen, and lungs, and slightly in kidneys for 7 days in mice $(>80 \%) .{ }^{22}$ Cho et al reported the accumulation of fluorescence dye-labeled silica nanoparticles of $50 \mathrm{~nm}$, $100 \mathrm{~nm}$, or $200 \mathrm{~nm}$ in liver, spleen, and kidneys at 24 hours post-injection, and their persistence in liver and spleen at 4 weeks in mice. ${ }^{24}$ On the other hand, Malfatti et al investigated the long-term biodistribution of carbon-14-labeled silica nanoparticles of $33 \mathrm{~nm}$ in mice, and demonstrated their persistence in the RES of liver, spleen, and lungs over 56 days following injection. ${ }^{25}$ Taking our result and those of others into account, it appears that the liver, spleen, lungs, and kidneys are targeted by silica nanoparticles regardless of animal, silica type, or exposure routes.

However, no report has demonstrated the in vivo biological fate of silica nanoparticles. In the present study, TEM images confirmed the presence of silica nanoparticles in target tissues. Interestingly, clear intact spherical silica particles with almost the pre-administered particle size (Table 1 and Figure 3) were found in livers treated with $20 \mathrm{~nm}$ and $100 \mathrm{~nm}$ nanoparticles. The intracellular localization of nanoparticles was determined to be hepatocytes as well as nuclei regardless of particle size. It was reported that silica nanoparticles are internalized into cells, localized throughout cellular compartments, and subsequently penetrate into the cell nucleus. ${ }^{30,31}$ Thus, the toxicity of silica nanoparticles in terms of inhibition of gene expression has to be considered. Nanoparticles with an irregular (decomposed) morphology were observed in kidneys, especially when $20 \mathrm{~nm}$ particles were administered. The presence of $\mathrm{Si}$ in the particulate forms was also confirmed by TEM-EDS. This result strongly suggests that silica nanoparticles were sequestered into liver in their intact particulate forms, but slowly decomposed or dissolved in kidneys.

The excretion kinetics study showed that nanoparticles can be eliminated by urinary excretion over 2 and 5 days following the administration of $500 \mathrm{mg} / \mathrm{kg}$ and $1,000 \mathrm{mg} / \mathrm{kg}$ $20 \mathrm{~nm}$ particles, respectively, whereas slower excretion profiles (over 3 and 6 days) were observed for $100 \mathrm{~nm}$ particles. This result implies that smaller silica nanoparticles are more rapidly eliminated from the body, possibly due to their greater decomposition rates in the kidneys (Figure 3). Furthermore, molecules with a hydrodynamic diameter of $<6 \mathrm{~nm}$ can pass through the glomerular membrane, ${ }^{32}$ thus, the presence of silica nanoparticles in kidneys and urine suggests that the nanoparticles are biodegraded prior to urinary excretion. It was reported that silica nanoparticles undergo gradual biodegradation both in vitro and in vivo, resulting in the formation of silicic acid (ortho-, meta-, di-, and trisilicates) by hydrolysis. ${ }^{33,34}$ Predominant excretion forms of silica nanoparticles in urine are known to be silicic acid or oligomeric silica species. ${ }^{35,36}$ Thus, sodium or potassium silicic acid salts could be excreted from the organs with the urine. Furthermore, it seems that absorbed nanoparticles (about 6.6\%-9.7\%) are excreted by the urinary system. However, the majority of nanoparticles (about 75\%-80\%) were directly excreted via feces, regardless of particle size or sex (Table 3). This finding suggests that fecal and biliary excretion routes play major roles in the elimination of silica nanoparticles. In the present study, it was likely that $10 \%-15 \%$ of administered nanoparticles remain in body tissues. Several studies have demonstrated the urinary excretion of silica nanoparticles, but after intravenous injection. In one study, in vivo fluorescence imaging system in mice showed that $45 \mathrm{~nm}$ silica nanoparticles were eliminated via the renal route. ${ }^{20}$ In another study, the urinary excretion of mesoporous silica nanoparticles (80-360 nm) was followed using a real-time in vivo imaging system, ${ }^{23}$ and, in another, $36 \%$ of $150 \mathrm{~nm}$ silica particles were reported to be excreted over 4 days in urine. ${ }^{29}$ However, the fecal excretion route was not examined in these studies. Huang et al and Cho et al investigated both the fecal and urinary excretions of silica nanoparticles in mice, ${ }^{22,24}$ but they did not calculate the amounts of silica particles excreted via urine and feces. Based on our findings and previous results in the literature, both renal and fecal routes are involved in the elimination of silica nanoparticles.

\section{Conclusion}

The effects of particle size $(20 \mathrm{~nm}$ and $100 \mathrm{~nm})$ on the tissue distribution and excretion of colloidal silica nanoparticles were investigated following a single oral administration to male and female rats. Nanoparticles were found to target the kidneys, liver, lungs, and spleen regardless of particle size or sex. The primary biological fate of silica nanoparticles was found to be in particulate form in tissues. Specifically, intact particulates were found in liver, but decomposed morphologies of particulates were observed in kidneys, suggesting possible nanoparticle degradation in vivo. Urinary 
and fecal excretion kinetics were found to be size-dependent, and $20 \mathrm{~nm}$ nanoparticles were eliminated faster that $100 \mathrm{~nm}$ nanoparticles, possibly due to the more rapid decomposition of $20 \mathrm{~nm}$ nanoparticles. These findings will be of interest to researchers seeking to predict the potential toxicological effects of silica nanoparticles on target organs.

\section{Acknowledgments}

This research was supported by a grant (10182MFDS991) from the Ministry of Food and Drug Safety in 2011, and partly by the Basic Science Research Program through the National Research Foundation of Korea (NRF), funded by the Ministry of Education, Science and Technology (2013R1A1A3009283).

\section{Disclosure}

The author reports no conflicts of interest in this work.

\section{References}

1. Douroumis D, Onyesom I, Maniruzzaman M, Mitchell J. Mesoporous silica nanoparticles in nanotechnology. Crit Rev Biotechnol. 2013;33(3): 229-245.

2. Lin W, Huang YW, Zhou XD, Ma Y. In vitro toxicity of silica nanoparticles in human lung cancer cells. Toxicol Appl Pharmacol. 2006;217(3):252-259.

3. Yang P, Gai S, Lin J. Functionalized mesoporous silica materials for controlled drug delivery. Chem Soc Rev. 2012;41(9):3679-3698.

4. Fang IJ, Trewyn BG. Application of mesoporous silica nanoparticles in intracellular delivery of molecules and proteins. Methods Enzymol. 2012;508:41-59.

5. Wei H, Zhou L, Li J, Liu J, Wang E. Electrochemical and electrochemiluminescence study of $\mathrm{Ru}(\mathrm{bpy})(2+) 3$-doped silica nanoparticles with covalently grafted biomacromolecules. J Colloid Interface Sci. 2008;321(2):310-314.

6. Nakamura M, Shono M, Ishimura K. Synthesis, characterization, and biological applications of multifluorescent silica nanoparticles. Anal Chem. 2007;79(17):6507-6514.

7. Volle JN, Chambon G, Sayah A, Reymond C, Fasel N, Gijs MA. Enhanced sensitivity detection of protein immobilization by fluorescent interference on oxidized silicon. Biosens Bioelectron. 2003;19(5): 457-464.

8. Luo D, Han E, Belcheva N, Saltzman WM. A self-assembled, modular DNA delivery system mediated by silica nanoparticles. J Control Release. 2004;95(2):333-341.

9. Chen JF, Ding HM, Wang JX, Shao L. Preparation and characterization of porous hollow silica nanoparticles for drug delivery application. Biomaterials. 2004;25(4):723-727.

10. Hirsch LR, Stafford RJ, Bankson JA, et al. Nanoshell-mediated nearinfrared thermal therapy of tumors under magnetic resonance guidance. Proc Natl Acad Sci U S A. 2003;100(23):13549-13554.

11. Tao Z, Morrow MP, Asefa T, et al. Mesoporous silica nanoparticles inhibit cellular respiration. Nano Lett. 2008;8(5):1517-1526.

12. Di Pasqua AJ, Sharma KK, Shi YL, et al. Cytotoxicity of mesoporous silica nanomaterials. J Inorg Biochem. 2008;102(7):1416-1423.

13. Slowing II, Wu CW, Vivero-Escoto JL, Lin VS. Mesoporous silica nanoparticles for reducing hemolytic activity towards mammalian red blood cells. Small. 2009;5(1):57-62.

14. Lin YS, Haynes CL. Impacts of mesoporous silica nanoparticle size, pore ordering, and pore integrity on hemolytic activity. J Am Chem Soc. 2010;132(13):4834-4842.
15. Kaewamatawong T, Shimada A, Okajima M, et al. Acute and subacute pulmonary toxicity of low dose of ultrafine colloidal silica particles in mice after intratracheal instillation. Toxicol Pathol. 2006;34(7): 958-965.

16. Liu T, Li L, Teng X, et al. Single and repeated dose toxicity of mesoporous hollow silica nanoparticles in intravenously exposed mice. Biomaterials. 2011;32(6):1657-1668.

17. Yu T, Hubbard D, Ray A, Ghandehari H. In vivo biodistribution and pharmacokinetics of silica nanoparticles as a function of geometry, porosity and surface characteristics. J Control Release. 2012;163(1): 46-54.

18. van Schooneveld MM, Vucic E, Koole R, et al. Improved biocompatibility and pharmacokinetics of silica nanoparticles by means of a lipid coating: a multimodality investigation. Nano Lett. 2008;8(8): 2517-2525

19. Park YH, Bae HC, Jang Y, et al. Effect of the size and surface charge of silica nanoparticles on cutaneous toxicity. Mol Cell Toxicol. 2013;9(1): 67-74.

20. He X, Nie H, Wang K, Tan W, Wu X, Zhang P. In vivo study of biodistribution and urinary excretion of surface-modified silica nanoparticles. Anal Chem. 2008;80(24):9597-9603.

21. Xie G, Sun J, Zhong G, Shi L, Zhang D. Biodistribution and toxicity of intravenously administered silica nanoparticles in mice. Arch Toxicol. 2010;84(3):183-190.

22. Huang X, Li L, Liu T, et al. The shape effect of mesoporous silica nanoparticles on biodistribution, clearance, and biocompatibility in vivo. ACS Nano. 2011;5(7):5390-5399.

23. He Q, Zhang Z, Gao F, Li Y, Shi J. In vivo biodistribution and urinary excretion of mesoporous silica nanoparticles: effects of particle size and PEGylation. Small. 2011;7(2):271-280.

24. Cho M, Cho WS, Choi M, et al. The impact of size on tissue distribution and elimination by single intravenous injection of silica nanoparticles. Toxicol Lett. 2009;189(3):177-183.

25. Malfatti MA, Palko HA, Kuhn EA, Turteltaub KW. Determining the pharmacokinetics and long-term biodistribution of $\mathrm{SiO}_{2}$ nanoparticles in vivo using accelerator mass spectrometry. Nano Lett. 2012;12(11): 5532-5538.

26. Paek HJ, Chung HE, Lee JA, et al. Quantitative determination of silica nanoparticles in biological matrices and their pharmacokinetics and toxicokinetics in rats. Adv Sci Mater. In press 2014.

27. Fu C, Liu T, Li L, Liu H, Chen D, Tang F. The absorption, distribution, excretion and toxicity of mesoporous silica nanoparticles in mice following different exposure routes. Biomaterials. 2013;34(10): 2565-2575.

28. Ivanov S, Zhuravsky S, Yukina G, Tomson V, Korolev D, Galagudza M. In vivo toxicity of intravenously administered silica and silicon nanoparticles. Materials. 2012;5(10):1873-1889.

29. Borak B, Biernat P, Prescha A, Baszczuk A, Pluta J. In vivo study on the biodistribution of silica particles in the bodies of rats. Adv Clin Exp Med. 2012;21(1):13-18.

30. Chen M, von Mikecz A. Formation of nucleoplasmic protein aggregates impars nuclear function in response to $\mathrm{SiO}_{2}$ nanoparticles. Exp Cell Res. 2005;305(1):51-62.

31. Hemmerich PH, von Mikecz AH. Defining the subcellular interface of nanoparticles by live-cell imaging. PloS One. 2013;8(4):e62018.

32. Deen WM, Lazzara MJ, Myers BD. Structural determinants of glomerular permeability. Am J Physiol Renal Physiol. 2001;281(4):F579-F596.

33. Galagudza M, Korolev D, Postnov V, et al. Passive targeting of ischemicreperfused myocardium with adenosine-loaded silica nanoparticles. Int J Nanomedicine. 2012;7:1671-1678.

34. Finnie KS, Waller DJ, Perret FL, et al. Biodegradability of sol-gel silica nanoparticles for drug delivery. J Sol-Gel Sci Technol. 2009;49:12-18.

35. Rosenholm JM, Mamaeva V, Sahlgren C, Lindén M. Nanoparticles in targeted cancer therapy: mesoporous silica nanoparticles entering preclinical development stage. Nanomedicine-UK. 2012;7(1):111-120.

36. Martin KR. The chemistry of silica and its potential health benefits. J Nutr Health Aging. 2007;11(2):94-97. 


\section{Publish your work in this journal}

The International Journal of Nanomedicine is an international, peerreviewed journal focusing on the application of nanotechnology in diagnostics, therapeutics, and drug delivery systems throughout the biomedical field. This journal is indexed on PubMed Central, MedLine, CAS, SciSearch $\AA$, Current Contents ${ }^{\circledR} /$ Clinical Medicine,

Journal Citation Reports/Science Edition, EMBase, Scopus and the Elsevier Bibliographic databases. The manuscript management system is completely online and includes a very quick and fair peer-review system, which is all easy to use. Visit http://www.dovepress.com/ testimonials.php to read real quotes from published authors.

Submit your manuscript here: http://www.dovepress.com/international-journal-of-nanomedicine-journal 